\title{
ORIENTASI PEMBELAJARAN DAN PERILAKU KERJA INOVATIF (PERAN EFIKASI DIRI KREATIF PADA UKM)
}

\author{
Noerchoidah 1 , * \\ Fakultas Ekonomi dan Bisnis, Universitas PGRI Adi Buana Surabaya, Surabaya, Indonesia \\ noerchoidah@unipasby.ac.id \\ *Corresponding author \\ Nurdina ${ }^{2}$ \\ Fakultas Ekonomi dan Bisnis, Universitas PGRI Adi Buana Surabaya, Surabaya, Indonesia, \\ nurdina@unipasby.ac.id \\ Tri Ariprabowo 3 \\ Fakultas Ekonomi dan Bisnis, Universitas PGRI Adi Buana Surabaya, Surabaya, Indonesia, \\ tri.ariprabowo@unipasby.ac.id
}

\begin{abstract}
Background - In the dynamic era of the business world, achieving business growth and sustainability requires human resources who have innovative skills. SMEs play an important role in the economic growth of a country. However, the added value provided is still not significant because the human resources owned by SMEs are still relatively low in innovative abilities. The solution is to conduct learning orientation and innovative behavior with the mediating role of creative self-efficacy.
\end{abstract}

Objectives - To provide new insights about the innovative behavior of SMEs, the extent to which learning orientation for innovative activities and creative self-efficacy influence the innovative behavior of SMEs.

Design/method/approach - This study uses quantitative methods. Respondent data was collected using a questionnaire. The sample used was 105 SMEs in Surabaya using the purposive sampling technique. Hypothesis testing using Partial Least Square (PLS).

Findings - The results of this study that learning orientation has a significant effect on creative self-efficacy and innovative work behavior, creative self-efficacy has a significant effect on innovative work behavior. Furthermore, creative self-efficacy plays a role in mediating learning orientation and innovative work behavior. Research Implications - For business continuity to be maintained, SMEs must produce products that are different from competitors. SMEs must increase learning opportunities to produce highly innovative work behavior.

Research Limitations - This study only involved SMEs in Surabaya so that future researchers should conduct similar research in a wider area for more comprehensive results.

Keywords: learning, orientation, creative, self, efficacy, innovative

\begin{abstract}
Abstrak
Latar belakang - Di era dunia bisnis yang dinamis untuk mencapai pertumbuhan dan keberlanjutan bisnis memerlukan sumber daya manusia yang memiliki keterampilan inovatif. UKM berperan penting dalam pertumbuhan ekonomi suatu negara. Namun, nilai tambah yang diberikan masih belum signifikan karena sumber daya manusia yang dimiliki UKM masih kemampuan inovatif relatif rendah. Solusinya dengan melakukan orientasi pembelajaran dan perilaku inovatif dengan peran mediasi efikasi diri kreatif.

Tujuan - Memberikan wawasan baru tentang perilaku inovatif UKM, sejauhmana orientasi pembelajaran untuk kegiatan inovatif, dan efikasi diri kreatif mempengaruhi perilaku inovatif UKM.
\end{abstract}


Desain / metode / pendekatan - Penelitian ini menggunakan metode kuantitatif. Data responden dikumpulkan menggunakan kuesioner. Sampel yang digunakan sebanyak 105 pelaku UKM di Surabaya dengan menggunakan teknik purposive sampling. Pengujian hipotesis menggunakan Partial Least Square (PLS).

Temuan - Hasil penelitian ini bahwa orientasi pembelajaran berpengaruh signifikan pada efikasi diri kreatif dan perilaku kerja inovatif, efikasi diri kreatif berpengaruh signifikan pada perilaku kerja inovatif. Selanjutnya, Efikasi diri kreatif berperan memediasi orientasi pembelajaran dan perilaku kerja inovatif.

Implikasi Penelitian - Keberlangsungan bisnis agar bisa dipertahankan maka UKM harus menghasilkan produk berbeda dengan pesaing. Pelaku UKM harus meningkatkan kesempatan belajar untuk menghasilkan perilaku kerja inovatif yang tinggi.

Batasan Penelitian - Penelitian ini hanya melibatkan pelaku UKM di Surabaya sehingga peneliti selanjutnya agar melakukan penelitian serupa di wilayah yang lebih luas lagi untuk hasil yang lebih komprehensif.

Kata kunci: orientasi, pembelajaran, efikasi, diri, kreatif, inovatif

\section{PENDAHULUAN}

Usaha Kecil Menengah (UKM) memiliki peranan penting terhadap pertumbuhan ekonomi suatu negara. UKM berkontribusi dalam mendorong pertumbuhan ekonomi sekaligus mengatasi krisis di Indonesia. Pada saat krisis ekonomi banyak usaha besar mengalami kontraksi, namun keberadaan usaha kecil dan menenga (UKM) tetap dapat bertahan sebagai tulang punggung perekonomian nasional (Karadag, 2016). UKM tetap dapat bertahan sebagai tulang punggung perekonomian nasional.

Berdasarkan data Kementerian Koperasi dan UKM bahwa UKM memiliki peran signifikan dalam menampung tenaga kerja sebesar 96,9\% dan berkontribusi pada Produk Domistik Bruto (PDB) sebesar 57,56\%. Menurut Kementrian Perindustrian tahun 2019 sebagai salah satu indikasi daya saing UKM Indonesia relatif masih rendah dibandingkan negara ASEAN. Diperkuat dengan Riset Bank Indonesia (2015) menjelaskan daya saing UKM di Indonesia secara garis besar masih kalah dengan negara seperti Singapura dan Malaysia. Dalam hal ini bahwa UKM tidak mampu bersaing dengan negara ASEAN karena kurang kompetitif atas produk yang dihasilkan. Hal ini dilatar belakangi kurangnya sumber daya manusia UKM yang handal dan kemampuan inovasi masih relatif rendah.

Era dunia bisnis yang sangat dinamis, perubahan yang cepat dan tingkat ketidakpastian lingkungan yang tinggi memerlukan keterampilan inovatif untuk mencapai pertumbuhan dan keberlanjutan UKM. Sumber daya manusia yang memiliki perilaku inovatif sangat diperlukan agar UKM dapat bertahan dan mengembangkan bisnis (Omri, 2015). UKM memiliki peran penting dalam pertumbuhan ekonomi suatu negara, namun nilai tambah yang diberikan masih belum signifikan. Hal ini karena sumber daya manusia yang dimiliki UKM masih memiliki kemampuan inovatif tergolong rendah (Ionica, 
2013). Menurut Begonja et al. (2016) bahwa suatu bisnis dengan sumber daya yang inovatif akan mampu meningkatkan produksi dan pangsa pasar. Kondisi saat ini, perubahan yang sangat dinamis dan tingginya tingkat ketidakpastian bergantung pada kemampuan sumber daya manusia yang memiliki perilaku inovatif untuk keberlanjutan UKM. Secara umum, penelitian sebelumnya menegaskan hubungan positif antara berbagi pengetahuan dengan perilaku inovatif (Nguyen et al., 2019; Kmieciak, 2020), efikasi diri kreatif pada perilaku inovatif (Seo et al., 2016), kepemimpinan diri (Omri, 2015), dan orientasi pembelajaran pada perilaku inovatif (Atitumpong \& Badir, 2018). Namun, belum ditemukan penelitian yang menunjukkan secara lebih rinci bentuk orientasi pembelajaran dan efikasi diri kreatif mempengaruhi proses perilaku inovatif yang terpisah. Selanjutnya, sampai saat ini, penelitian tentang hubungan antara orientasi pembelajaran dan perilaku inovatif belum mempertimbangkan peran mediasi efikasi diri kreatif.

Para peneliti umumnya setuju bahwa inovasi adalah proses multifaset dan kompleks (Lee et al., 2019). Dalam proses ini, kreativitas sering dianggap sebagai elemen inovasi. Namun, saling ketergantungan antara kreativitas dan inovasi tetap ambigu. Amabile (2013) menunjukkan bahwa kreativitas sering dilihat sebagai penciptaan ide atau solusi yang berusaha untuk menjadi berbeda mungkin dari ide-ide yang ada, sedangkan inovasi adalah realisasi konkret dari ide-ide atau solusi baru. Lee et al. (2019) menegaskan bahwa dalam proses inovasi, kreativitas adalah perumusan ide-ide baru sedangkan inovasi adalah pelaksanaan aktual dari ide-ide ini ke dalam praktik atau penggunaan praktis. Sejalan dengan pemikiran beberapa penulis, terutama Lee et al. (2019) yang mengasumsikan perilaku inovatif sebagai proses multi tahap yang mencakup kreativitas dan implementasi. Perilaku kerja inovatif sebagai sumber keberhasilan organisasi (Lee et al., 2019). Yuan \& Woodman (2010) mendefinisikan perilaku kerja inovatif sebagai penciptaan dan penerapan yang disengaja dari ide atau inovasi baru (produk atau proses baru) di tempat kerja untuk meningkatkan kinerja individu, kelompok, atau organisasi. Perilaku kerja yang inovatif adalah konsep kompleks yang dapat mencakup aktivitas perilaku seperti eksplorasi ide, pembangkitan, promosi, dan implementasi (Lee et al., 2019). Efikasi diri kreatif dapat ditelusur dari Tierney \& Farmer (2011). Bandura (2011) telah mendefinisikan keyakinan diri sebagai sesuatu yang mengacu pada keyakinan pada kemampuan seseorang untuk memobilisasi motivasi, sumber daya kognitif, dan tindakan 
yang diperlukan untuk memenuhi tuntutan situasional yang diberikan. Bandura (2011) mengutip efikasi diri yang kuat sebagai kondisi yang diperlukan untuk produktivitas kreatif dan penemuan pengetahuan baru. Pandangan efikasi diri mempengaruhi motivasi dan kemampuan untuk terlibat dalam perilaku tertentu serta mengejar tugastugas tertentu. Konsep efikasi diri menjanjikan banyak untuk memahami tindakan kreatif dalam organisasi. Ford (1996) menempatkan efikasi diri sebagai komponen motivasi utama dalam model tindakan kreatif individunya. Individu dengan orientasi pembelajaran sangat termotivasi untuk belajar dan memandang pengetahuan sebagai sesuatu yang berharga (Jha \& Bhattacharyya, 2013).

Penelitian ini membahas tentang gap dan mengembangkan model penelitian untuk menghubungkan orientasi pembelajaran dalam suatu organisasi, efikasi diri kreatif individu dalam suatu organisasi dan perilaku inovatif. Selain itu, penelitian ini meneliti pengaruh mediasi efikasi diri kreatif pada hubungan antara orientasi pembelajaran dan perilaku inovatif. Tujuan dari penelitian ini adalah untuk memberikan wawasan baru tentang perilaku inovatif UKM, sejauh mana orientasi pembelajaran dilakukan untuk kegiatan inovatif, dan efikasi diri kreatif mempengaruhi perilaku inovatif UKM.
Penelitian difokuskan pada wilayah Surabaya karena memiliki jumlah UKM terbanyak dan perkembangan yang cukup pesat di Jawa Timur. Selain itu Surabaya juga merupakan salah satu kota yang menjadi pusat UMKM di Jawa Timur dan juga menjadi sorotan Nasional.

\section{TINJAUAN PUSTAKA}

\section{Orientasi Pembelajaran}

Pembelajaran organisasi mengacu pada perhatian individu untuk pengembangan pengetahuan, ketrampilan, kompetensi, dan wawasan baru dan memiliki potensi untuk menciptakan produk dan layanan yang unggul dari pesaing (Slater \& Narver, 1995). Tujuan pencapaian pembelajaran memotivasi individu untuk memperoleh pengetahuan, keterampilan dan pengalaman baru dan untuk fokus pada peningkatan kompetensi mereka sendiri dan mengeksplorasi pengetahuan atau keterampilan baru (Elliot \& Church, 1997). Akibatnya, mereka akan mencari tugas-tugas yang menantang dan kompleks karena tujuan pencapaian pembelajaran memfasilitasi pembelajaran dan meningkatkan jumlah strategi yang dieksplorasi dan pengetahuan (Miron-Spektor \& Beenen, 2015). Lemon \& Sahota (2004) menyatakan bahwa pembelajaran berperan penting dalam memastikan bahwa pengetahuan terus diperbarui untuk perilaku 
kerja yang sesuai dengan perubahan lingkungan yang kompetitif. Alegre \& Chiva (2013) menyatakan bahwa orientasi pembelajaran sebagai kapasitas inovasi berbasis tindakan untuk memperkenalkan dan mengimplementasikan ide-ide baru.

\section{Kepercayaan Diri Kreatif}

Efikasi diri adalah mekanisme yang berkenaan dengan social cognitive theory. Atas dasar ini, teori Bandura mengemukakan bahwa seseorang dengan efikasi diri yang tinggi lebih sering memandang tugas yang menantang sebagai sesuatu yang dapat dikuasai dan bukan untuk dihindari Bandura (2011). Implikasi dari ini menghubungkan konstruk efikasi diri dengan bagaimana seseorang secara kognitif mengevaluasi tugas pekerjaan tertentu tergantung pada tingkat efikasi orang tersebut (tinggi atau rendah) (Sousa et al., 2012). Efikasi diri kreatif merupakan perluasan dari konstruksi efikasi diri. Efikasi diri kreatif oleh Tierney \& Farmer (2011), didefinisikan sebagai keyakinan seseorang memiliki kemampuan untuk menghasilkan hasil yang kreatif. Individu yang merasa memiliki efikasi diri kreatif cenderung terlibat dalam pencarian informasi yang lebih luas (Tierney \& Farmer, 2011) dan lebih cenderung mengakses pengetahuan dan keahlian yang relevan dari anggota tim lain yang diperlukan untuk mengembangkan ideide baru dan berguna.

\section{Perilaku Kerja Inovatif}

Di era perubahan yang cepat saat ini, organisasi menghadapi permintaan yang lebih besar dari lingkungan untuk terlibat dalam perilaku inovatif dalam menciptakan dan memberikan produk dan/atau layanan mereka agar tetap kompetitif. Untuk itu, organisasi mendorong karyawan untuk berinovasi dalam proses, metode, dan operasi mereka. Karyawan secara individu harus terlibat dalam perilaku kerja inovatif jika organisasi ingin mendapatkan manfaat dari perilaku tersebut. Perilaku kerja inovatif didefinisikan sebagai pengembangan, mengadopsi, dan implementasi gagasan baru untuk produ, teknologi dan metode kerja oleh karyawan sering dikalim sebagai penentu penting kesuksesan organisasi (Yuan \& Woodman, 2010). Proses inovasi diawali adanya masalah yang perlu dipecahkan yang menjadi dasar penciptaan ide-ide baru karyawan (Lee et al. (2019). Selanjutnya, karyawan secara individu harus mempromosikan ide-ide baru dengan mencari dukungan untuk implementasi sebagai produk nyata, jasa, metode atau tehnik (Thurlings et al., 2015). Perilaku inovatif melibatkan baik generasi dan implementasi ide-ide kreatif dalam lingkungan kerja. Kreativitas dalam konteks organisasi dapat dianggap sebagai jenis perilaku inovatif yang 
mencakup tidak hanya menghasilkan ide baru dan berguna tetapi juga memperkenalkan ide-ide baru orang lain ke organisasi seseorang (Yuan \& Woodman, 2010).

\section{Hipotesis}

Orientasi pembelajaran digambarkan sebagai adopsi dari proses pembelajaran dasar. Orientasi pembelajaran memainkan peran penting dalam memperbarui aset dan kemampuan mengenai kegiatan utamanya (Wang, 2016). Jika sebuah perusahaan kurang berorientasi pada pembelajaran dibandingkan para pesaingnya, perusahaan tersebut mengalami kesulitan besar dalam bertahan hidup. Orientasi pembelajaran adalah pola pikir internal yang memotivasi individu untuk mengembangkan kompetensinya. Individu dengan orientasi pembelajaran mencari tantangan yang memberi mereka kesempatan belajar (Ames \& Archer, 1988). Penelitian menunjukkan bahwa orientasi pembelajaran untuk perolehan pengetahuan dan keterampilan (Kozlowski et al., 2001). Orientasi pembelajaran sebagai penciptaan pengalaman atau pengamatan baru, memiliki kemungkinan dampak pada tindakan melalui ide-ide dan nilai-nilai (Jiménez-Jimenez et al., 2008). Orientasi Pembelajaran berkorelasi dengan penciptaan ketrampilan baru dalam organisasi (Rhee et al., 2010).
Perilaku inovatif individu berfokus pada adopsi dan implementasi ide, daripada menemukan rute tercepat untuk menyelesaikan tugas atau kekhawatiran tentang kinerja, yang terbaik adalah mengevaluasi pengaruh orientasi pembelajaran individu pada perilaku inovatif individu karyawan. Argumen ini didukung oleh Lu et al. (2012) bahwa penelitian lebih lanjut tentang hubungan antara orientasi belajar individu dan inovasi diperlukan. Kashif et al. (2019) menunjukkan bahwa orientasi pembelajaran karyawan secara individu berhubungan positif dengan kreativitas mereka. Kashif et al. (2019) menganggap bahwa pembelajaran sangat diperlukan untuk kreativitas. Generasi ide kreatif adalah batu loncatan untuk perilaku inovatif individu (Lee et al., 2019). Penelitian tentang orientasi pembelajaran individu telah menyoroti keuntungan dari orientasi pembelajaran individu dalam inovasi karyawan. Sementara penelitian sebelumnya telah menunjukkan hubungan positif antara pembelajaran dan perilaku inovatif individu di sektor swasta (Rhee et al., 2010). Berdasarkan penjelasan yang disampaikan diatas dapat dirumuskan hipotesis berikut.

H1: Orientasi Pembelajaran Berpengaruh Signifikan pada Kepercayaan Diri Kreatif

Perilaku inovatif karyawan sebagai modal manusia penting yang berkontribusi pada 
keunggulan kompetitif perusahaan karena keberhasilan implementasi ide-ide kreatif baru dan berguna yang ditawarkan oleh karyawan. Kreativitas telah menekankan keunikan individu kreatif serta pengaruh sifat kepribadian pada faktor motivasi dan perilaku inovatif. Berdasarkan teori kognitif sosial oleh Bandura (2011) bahwa efikasi diri kreatif mengarah pada tingkat perilaku inovatif yang lebih tinggi karena dua alasan utama. Individu yang tinggi efikasi diri kreatif cenderung memilih untuk terlibat dalam perilaku inovatif, karena merasa percaya diri dengan pengetahuan dan keterampilan mereka untuk menghasilkan ide-ide dan menerapkan ide-ide tersebut di tempat kerja (Jiang \& Gu, 2017). Konstruk efikasi diri kreatif diperluas dari efikasi diri dan didefinisikan sebagai keyakinan (atau keyakinan) yang mencerminkan kepercayaan diri seseorang dalam kemampuannya saat melakukan tugas inovasi (Tierney \& Farmer, 2011). Individu dengan efikasi diri kreatif yang tinggi dapat memobilisasi motivasi, sumber daya kognitif, dan tindakan yang diperlukan untuk memenuhi tuntutan situasional. Mereka menghabiskan lebih banyak waktu pada proses kognitif kreatif dalam pengenalan masalah serta generasi ide atau solusi, dan mereka membuat upaya yang lebih besar untuk mencari sponsor untuk ide-ide dan menghasilkan prototipe.
Mereka dapat melakukan tugas tertentu dengan sukses dan mencapai tujuan inovasi organisasi dalam menghadapi hambatan (Kashif et al., 2019). Individu dengan efikasi diri kreatif yang tinggi akan menghabiskan lebih banyak waktu pada proses kognitif kreatif dalam mengidentifikasi masalah dan menghasilkan ide untuk memecahkan masalah tersebut serta mencari sponsor untuk ide-ide tersebut dari mereka yang lebih tinggi dalam hierarki organisasi (Hsu et al., 2011) dan lebih siap untuk mengatasi tantangan dan ketidakpastian yang dihadapi ketika mengembangkan dan menerapkan ideide baru di tempat kerja (Richter et al., 2012). Hal tersebut menuju hipotesis berikut.

H2: Kepercayaan Diri Kreatif Berpengaruh Signifikan Pada Perilaku Kerja Inovatif

Orientasi pembelajaran mengacu pada dedikasi individu, dan perhatian untuk mengembangkan kemampuan, pengetahuan, keterampilan dan kompetensi seseorang dengan memperoleh dan berbagi informasi tentang kebutuhan pelanggan, perubahan pasar dan tindakan pesaing, serta pengembangan teknologi baru untuk menciptakan produk dan produk baru. layanan yang lebih unggul dari pesaing (Suliyanto \& Rahab, 2012). Individu dengan orientasi pembelajaran yang kuat terus menerus mencari cara untuk meningkatkan pengetahuan dan keterampilan. Individu 
seperti itu cenderung melihat tugas-tugas baru dan sulit, seperti perilaku kerja inovatif, sebagai tantangan dan sebagai peluang untuk belajar dalam menghadapi rintangan, umpan balik negatif dari rekan kerja, dan risiko kegagalan (Runhaar et al., 2016). Dengan demikian, umpan balik positif dan umpan balik negatif cenderung dilihat sebagai informasi yang relevan yang dapat membantu mereka untuk meningkatkan kemampuan mereka.

Orientasi pembelajaran diharapkan dapat meningkatkan perilaku inovatif dengan pengembangan keterampilan yang relevan dengan domain dan kreativitas. Keterampilan ini memberikan latar belakang pengetahuan penting dan dasar untuk pengembangan dan generasi sesuatu yang baru yang strategi yang diperlukan seringkali belum dipelajari. Untuk memperoleh pengetahuan dan keterampilan tersebut, individu harus terlibat dalam proses belajar. Individu yang berorientasi pembelajaran cenderung menghadapi tantangan dan hambatan dengan menginvestasikan upaya tambahan untuk mengembangkan dan menguasai keterampilan baru dan cenderung mengatasi secara efektif dengan umpan balik negatif dan positif (Ellström, 2010) dengan menempatkan upaya substansial ke dalam kegiatan pemecahan masalah kreatif untuk mengidentifikasi dan menerapkan strategi yang dibutuhkan untuk berhasil (Suliyanto \& Rahab, 2012).

Pembelajaran sangat penting untuk perilaku kerja inovatif (Holman et al., 2012). Bukti empiris menunjukkan bahwa perolehan pengetahuan dan keterampilan meningkatkan generasi ide (Ellström, 2010). Pengetahuan yang diperoleh ini juga dapat mempengaruhi seorang karyawan mempromosikan ide-ide kepada orang lain dan sejauh mana ide-ide mereka diimplementasikan (Holman et al., 2012). Dengan penjelasan di atas, hipotesis sebagai berikut.

H3: Orientasi Pembelajaran Berpengaruh Signifikan Pada Perilaku Kerja Inovatif

Penelitian ini mengembangkan dari penelitian sebelumnya tentag peran mediasi efikasi diri kreatif pada pengaruh orientasi belajar karyawan pada perilaku inovatif. Efikasi diri kreatif mencerminkan kepercayaan diri seseorang pada kemampuan untuk melakukan tugas tertentu dalam proses inovasi. Karyawan cenderung menampilkan tingkat pemecahan masalah dan keterlibatan proses kreatif yang lebih tinggi ketika mereka memiliki tingkat efikasi diri kreatif yang lebih tinggi (Tierney \& Farmer, 2011). Pengembangan kompetensi adalah hasil dari orientasi pembelajaran, membantu karyawan untuk mengakumulasi penguasaan keberhasilan. Akibatnya, 
karyawan menjadi lebih mandiri untuk menampilkan perilaku inovatif kerja karena peningkatan keterampilan dan pengalaman. Karyawan dengan efikasi diri yang tinggi cenderung percaya bahwa ide-ide inovatif yang mereka bawa dihargai oleh orang lain. Bandura (2011) menyatakan bahwa jika karyawan dengan efisiensi tinggi tidak dapat mengumpulkan dukungan untuk mendukung ide-ide mereka, mereka tidak akan terpengaruh secara kuat karena mereka selalu menemukan cara untuk memperbaiki diri. Selain itu, mereka secara efektif menyelesaikan konflik dan penolakan dari rekan kerja yang mungkin terjadi bersamaan dengan inovasi (Ergeneli et al., 2010).
Orientasi pembelajaran membantu meningkatkan kompetensi diri yang merupakan bagian penting dari perilaku inovatif kerja, karena adanya resiko, ketidakpastian dan menantang Bandura (2011). Karyawan berhasil mengatasi kegagalan dan ketidakpastian ketika mereka percaya diri dan menerapkan tugas-tugas inovatif. Berdasarkan alasan dan pembahasan tersebut di atas, maka diajukan hipotesis berikut:

H4: Kepercayaan Diri Kreatif Memediasi Hubungan Orientasi Pembelajaran dan Perilaku Kerja Inovatif.

\section{Kerangka Penelitian}



Gambar 1

Kerangka Penelitian

\section{METODOLOGI PENELITIAN}

Populasi dalam penelitian ini adalah pelaku UKM yang tersebar di Surabaya yang jumlahnya tidak diketahui sehingga penentuan banyaknya jumlah sampel yang digunakan dalam penelitian ini mengacu 
pada pendapat (Hair et al., 2010), yaitu 5-10 parameter kali banyaknya indikator. Indikator pada penelitian ini sebanyak 18 sehingga jumlah minimal sampel yang harus ada sebanyak 18 × $5=90$, namun jumlah sampel yang digunakan dalam penelitian ini sebanyak 105. Hal ini dimaksudkan semakin besar sampel yang digunakan akan diperoleh data yang semakin akurat.

Variabel orientasi pembelajaran terdiri 5 indikator dengan menggunakan instrumen pengukuran dari (Sujan et al., 1994), yaitu: mempelajari metode baru, menghabiskan lebih banyak waktu dan tenaga untuk pekerjaan, pengambilan keputusan didasarkan kesepakatan, berbagi pengetahuan dan bertanya adalah hal penting, memberi ide-ide baru. Contoh item: Saya belajar hal baru dalam pekerjaan saya. Variabel efikasi diri kreatif sebanyak 7 indikator menggunakan instrumen dari Tierney \& Farmer (2011), yaitu dapat menyelesaikan masalah yang rumit secara efisien, memercayai kemampuan kreatif diri sendiri, keyakinan memiliki imajinasi dan kecerdikan, dapat mengatasi situasi sulit, yakin dapat menangani masalah yang membutuhkan pemikiran kreatif, pandai mengusulkan solusi orisinal untuk masalah, keyakinan memiliki ide-ide baru. Contoh item: Saya yakin dapat mengembangkan usaha ini. Selanjutnya, variabel perilaku kerja inovatif sebanyak 6 indikator menggunakan instrumen dari (Lee et al., 2019) yaitu: mengemukakan ide-ide baru,mencari metode kerja baru melakukan hal-hal baru terkait pekerjaan, bersedia dan mengadaptasi ide-ide baru, memperjuangkan gagasan baru dengan gigih. Contoh item: Saya berusaha mencari metode kerja baru

Pengambilan sampel menggunakan purposive sampling yaitu pengambilan sampel dengan menggunakan kriteria tertentu, yaitu: pelaku usaha UKM telah menjalankan bisnisnya minimal 1 tahun dan omset yang dihasilkan lebih besar dari 300.000.000 per tahun. Pengukuran jawaban responden menggunakan skala Likert $1-5$ poin, yaitu $1=$ sangat tidak setuju, $2=$ tidak setuju, $3=$ netral, $4=$ setuju, 5 = sangat setuju. Analisis data penelitian ini menggunakan Partial Least Square (PLS).

\section{HASIL DAN PEMBAHASAN}

\section{Model Pengukuran (Outer Model)}

Pengujian validitas konvergen meliputi nilai loading factor dan Average Variance Extracted (AVE). Pengujian reliabilitas dapat dilihat dari nilai composite reliability (CR). Dalam penelitian ini suatu indikator dikatakan valid apabila memiliki nilai loading factor lebih dari 0.7 dan nilai AVE lebih besar dari 0.5. lebh lanjut tabel 1 menggambarkan hasil uji ini secara statistik. 
Tabel 1 diketahui bahwa seluruh variabel orientasi pembelajaran, efikasi diri kreatif, dan perilaku kerja inovatif memiliki nilai loading factor lebih besar dari 0.7 dan nilai AVE lebih besar dari 0.5. Dengan demikian seluruh indikator adalah valid. Pada variabel orientasi pembelajaran nilai loading factor terbesar pada OP2. Variabel efikasi diri kreatif nilai loading factor terbesar pada EDK5, dan varibel perilaku kerja inovatif nilai loading factor terbesar pada PKI5. Lebih lanjut, untuk masing masing variabel adalah reliabel karena memiliki nilai Cronbach's Alpha lebih besar dari 0.6 dan nilai composite reliability (CR) lebih besar dari 0.7.

\section{Model Struktural (Inner Model)}

Model struktural digunakan untuk mengetahui hubungan antara variabel laten atau menguji hipotesis. Pengujian hipotesis digunakan untuk menguji hubungan antara variabel bebas dengan variabel terikat dengan melihat nilai t-statistik pada masing-masing path. Dengan menggunakan software PLS, nilai t-statistik dapat diperoleh dari bootstrap. Dengan menggunakan t-tabel dua sisi dengan tingkat signifikasi 5\% maka t-tabel sebesar 1.96. lebh lanjut tabel 2 menggambarkan hasil uji ini secara statistik.

Berdasarkan Tabel 2 terdapat pengaruh langsung orientasi pembelajaran terhadap efikasi diri kreatif sebesar 0.378 dan $\mathrm{t}$ statistik 3.347 lebih besar dari t-tabel 1.96 dan $\mathrm{p}$-value $(0.000)<0.05$, sehingga $\mathrm{H}_{1}$ yang menyebutkan orientasi pembelajaran berpengaruh signifikan pada efikasi diri kreatif didukung. Hal ini berarti bahwa semakin tinggi orientasi pembelajaran yang diberikan bagi pelaku UKM maka dapat meningkatkan efikasi diri kreatif pelaku UKM di Surabaya. Orientasi pembelajaran bagi pelaku UKM dapat memotivasi untuk mengembangkan kemampuan kompetensi yang dimiliki. Selain itu juga untuk keningkatkan efikasi diri kreatif khususnya perilaku adaptif untuk menghadapi kondisi lingkungan yang dinamis. Hasil penelitian ini sejalan dengan penelitian sebelumnya, seperti Fuadiputra (2020) dan Tran et al. (2018) bahwa orientasi pembelajaran berpengaruh positif dan signifikan pada efikasi diri kreatif karyawan. Temuan ini mendukung argumen sebelumnya bahwa pembelajaran berkelanjutan akan memberikan banyak kesempatan bagi karyawan untuk mengeksplorasi berbagai perspektif dan sudut pandang serta memperkuat basis pengetahuan untuk mengintensifkan keterampilan pemecahan masalah dan proses inovasi. Hal ini menunjukkan bahwa dengan meningkatkan kompetensi diri secara konsisten, individu yang berorientasi pada pembelajaran mampu mempertahankan keyakinan efikasi. Temuan tersebut juga menyiratkan bahwa karyawan 
dengan tingkat efikasi diri kreatif yang lebih tinggi lebih mungkin untuk menghasilkan hasil yang lebih inovatif (Tierney \& Farmer, 2011).

Tabel 1

Hasil Uji Validitas dan Reliabilitas

\begin{tabular}{lccccc}
\multicolumn{1}{c}{ Variabel } & Indikator & $\begin{array}{c}\text { Loading } \\
\text { Factor }\end{array}$ & AVE & $\begin{array}{c}\text { Cronbach's } \\
\text { Alpha }\end{array}$ & CR \\
& OP1 & 0.891 & & & \\
& OP2 & 0.924 & & & \\
Orientasi & OP3 & 0.762 & & & \\
Pembelajaran & OP4 & 0.708 & 0.788 & 0.769 & 0.842 \\
& OP5 & 0.816 & & & \\
& OP6 & 0.854 & & & \\
& OP7 & 0.764 & & & \\
& OP8 & 0.801 & & & \\
& EDK1 & 0.742 & & & \\
& EDK2 & 0.798 & & & \\
Efikasi Diri Kreatif & EDK3 & 0.837 & & & \\
& EDK4 & 0.765 & 0.721 & 0.785 & \\
& EDK5 & 0.921 & & & \\
& EDK6 & 0.853 & & & \\
& EDK7 & 0.769 & & & \\
& PKI1 & 0.786 & & & \\
& PKI2 & 0.882 & & & \\
PKI3 & 0.810 & & & \\
& PKI4 & 0.769 & 0.835 & & \\
& PKI4 & & & & \\
& PKI5 & 0.893 & & & \\
& PKI6 & 0.751 & & & \\
& PKI7 & 0.734 & & & \\
\end{tabular}

Sumber: Data diolah, 2021

Tabel 2

Pengaruh Langsung dan Tidak langsung Orientasi Pembelajaran (OP), Efikasi Diri Kreatif (EDK) Pada Perilaku Kerja Inovatif (PKI)

\begin{tabular}{|c|c|c|c|c|c|}
\hline Hipotesis & & Variabel & Koefisien Jalur & p-value & t-statistik \\
\hline $\mathrm{H}_{1}$ & OP & $\rightarrow \mathrm{EDK}$ & 0.378 & 0.000 & 3.347 \\
\hline $\mathrm{H}_{2}$ & EDK & $\rightarrow \mathrm{PKI}$ & 0.629 & 0.000 & 4.412 \\
\hline $\mathrm{H}_{3}$ & OP & $\rightarrow$ PKI & 0.482 & 0.000 & 4.281 \\
\hline $\mathrm{H}_{4}$ & OP & $\rightarrow \mathrm{EDK} \rightarrow \mathrm{PKI}$ & 0.787 & 0.000 & 3.852 \\
\hline
\end{tabular}

Sumber: Data diolah, 2021

Pengaruh langsung efikasi diri kreatif terhadap perilaku kerja inovatif memberikan nilai sebesar 0.629 dan t-statistik 4.412 lebih besar dari t-tabel 1.96 dan p-value $(0.000)<$
0.05, sehingga $\mathrm{H}_{2}$ yang menyebutkan efikasi diri kreatif berpengaruh signifikan pada perilaku kerja inovatif didukung. Hal ini memberikan makna bahwa semakin tinggi 
efikasi diri kreatif yang dimiliki pelaku UKM di Surabaya akan dapat meningkatkan perilaku kerja inovatif pelaku UKM di Surabaya. Pelaku UKM di Surabaya dengan efikasi diri kreatif tinggi akan memiliki kepercayaan mampu menghasilkan ide-ide kreatif. Dengan efikasi diri kreatif yang tinggi cenderung mencapai hasil kreatif. Dengan demikian mereka terlibat dalam perilaku inovatif karena mereka percaya pada pengetahuan dan keterampilan mereka untuk menghasilkan ide di tempat kerja. Hasil penelitian ini sejalan dengan penelitian Hsu et al. (2011) dan Newman et al. (2018) bahwa karyawan dengan tingkat efikasi diri kreatif tinggi mempengaruhi perilaku inovatif di tempat kerja.

Pengaruh langsung orientasi pembelajaran terhadap perilaku kerja inovatif memiliki nilai 0.482 dan t-statistik 4.281 lebih besar dari t-tabel 1.96 dan p-value $(0.000)<0.05$, sehingga $\mathrm{H}_{3}$ yang mengatakan orientasi pembelajaran berpengaruh signifikan terhadap perilaku kerja inovatif didukung. Hal ini memberikan makna semakin baik orientasi pembelajaran yang diberikan kepada pelaku UKM di Surabaya akan semakin meningkatkan perilaku kerja inovatif para pelaku UKM di Surabaya. Orientasi pembelajaran yang dilakukan akan berhubungan positif dengan kreativitas pelaku UKM. Adanya orientasi pembelajaran dapat meningkatkan perilaku inovatif dengan pengembangan keterampilan yang relevan dan kreativitas. Hal ini sesuai dengan pendapat Kashif et al. (2019) untuk kreativitas. Generasi ide kreatif adalah langkah awal untuk perilaku inovatif individu (Lee et al., 2019). Hasil penelitian ini konsisten dengan penelitian sebelumnya dari Mutonyi et al. (2020) dan Atitumpong \& Badir (2018) bahwa orientasi pembelajaran memiliki hubungan positif dengan perilaku inovatif individual.

Pengaruh tidak langsung kepercayaan diri kreatif memediasi hubungan orientasi pembelajaran dan perilaku kerja inovatif memiliki nilai sebesar 0.787 dan t-statistik 3.852 lebih besar dari t-tabel 1.96 dan p-value $(0.000)<0.05$, sehingga $\mathrm{H}_{4}$ didukung. Dengan demikian dapat dimaknai bahwa orientasi pembelajaran yang tinggi akan dapat meningkatkan perilaku kerja inovatif secara tidak langsung melalui efikasi diri kreatif. Hasil pengaruh langsung orientasi pembelajaran terhadap perilaku kerja inovatif sebesar 0.629, sedangkan untuk pengaruh tidak langsung orientasi pembelajaran terhadap perilaku kerja inovatif melalui mediasi efikasi diri kreatif sebesar 0.787 . Dengan demikian bahwa adanya mediasi efikasi diri kreatif memiliki peran yang besar daripada pengaruh langsung orientasi 
pembelajaran terhadap perilaku kerja inovatif.

\section{KESIMPULAN}

Penelitian ini meneliti pengaruh antara orientasi pembelajaran dan perilaku kerja inovatif dan peran mediasi efikasi diri kreatif. Hasil penelitian menunjukkan bahwa orientasi pembelajaran berpengaruh positif dan signifikan terhadap perilaku kerja inovatif. Selain itu, orientasi pembelajaran meningkatkan efikasi diri kreatif, yang pada gilirannya efikasi diri kreatif akan mendorong perilaku kerja yang inovatif. Dengan demikian, efikasi diri kreatif memediasi hubungan antara orientasi pembelajaran dan perilaku kerja inovatif. Orientasi pembelajaran tercermin pada setiap pelaku UKM di Surabaya untuk meningkatkan kemampuan, ketrampilan, dan kompetensinya untuk memiliki perilaku inovatif di tempat kerjanya. Orientasi pembelajaran merupakan aspek penting dalam menciptakan efikasi diri kreatif untuk mencapai perilaku karyawan yang inovatif karena orientasi pembelajaran memberikan peluang besar kepada para pelaku UKM di Surabaya untuk mengembangkan kreativitasnya. Orientasi pembelajaran meningkatkan efikasi diri kreatif pelaku UKM di Surabaya dalam proses inovasi dengan menghasilkan dan mengeksplor ide-ide baru dan menerapkannya dalam pekerjaan inovatif.

\section{IMPLIKASI PENELITIAN}

Hasil penelitian ini mengungkapkan peran penting efikasi diri dalam memediasi hubungan orientasi pembelajaran dan perilaku inovatif di tempat kerja. Ketika orientasi pembelajaran dilakukan pada tingkat tinggi pada pelaku UKM di Surabaya maka efikasi diri kreatif dan perilaku kerja inovatif dapat meningkat. Persaingan bisnis khususnya di sektor UKM di Surabaya semakin ketat. Persaingan yang begitu ketat menuntut UKM untuk mengembangkan inovasi dengan menghasilkan ide-ide inovatif yang mendorong pelaku UKM untuk meningkatkan perilaku inovatif di tempat kerja. Dalam mempertahankan keberlangsungan usaha, maka pelaku UKM harus mampu menghasilkan produk yang unik yang berbeda dengan pesaing. Oleh karenanya, peran pelaku UKM sangat diperlukan untuk lebih meningkatkan kesempatan belajar yang luas untuk meningkatkan pengetahuan, ketrampilan sehingga mampu menghasilkan ide-ide kreatif di tempat kerja untuk perilaku kerja inovatif yang tinggi. Penelitian ini hanya melibatkan pelaku UKM di Surabaya sehingga penelitian selanjutnya bisa diaplikasikan di tempat yang berbeda. Peneliti 
selanjutnya dapat melakukan pengembangan dari penelitian yang sudah dilakukan, misalnya dengan menambahkan kinerja kreatif.

\section{DAFTAR PUSTAKA}

Alegre, J., \& Chiva, R. (2013). Linking entrepreneurial orientation and firm performance: The role of organizational learning capability and innovation performance. Journal of Small Business Management, 51(4), 491-507. https://doi.org/10.1111/jsbm.12005

Amabile, T. (2013). A model of creativity and innovation in organizations. Research in Organizational Behavior, 10, 123-167.

Ames, C., \& Archer, J. (1988). Achievement Goals in the Classroom: Students' Learning Strategies and Motivation Processes. Journal of Educational Psychology, 80(3), 260-267. https://doi.org/10.1109/APCC.2016.7581477

Atitumpong, A., \& Badir, Y. F. (2018). Leader-member exchange, learning orientation and innovative work behavior. Journal of Workplace Learning, 30(1), 32-47. https://doi.org/10.1108/JWL-01-2017-0005

Bandura. (1997). Self-efficacy: The exercise of control. New York: Freeman.

Begonja, M., Čićek, F., Balboni, B., \& Gerbin, A. (2016). Innovation and business performance determinants of SMEs in the Adriatic region that introduced social innovation. Economic Research-Ekonomska Istrazivanja, 29(1), 1136-1149.

https://doi.org/10.1080/1331677X.2016.1213651

Elliot, A. J., \& Church, M. A. (1997). A Hierarchical Model of Approach and Avoidance Achievement Motivation. Journal of Personality and Social Psychology, 72(1), 218-232.

https://doi.org/10.1037/0022-3514.72.1.218

Ellström, P. E. (2010). Practice-based innovation: A learning perspective. Journal of Workplace Learning, 22(1-2), 27-40. https://doi.org/10.1108/13665621011012834

Ergeneli, A., Camgoz, S. M., \& Karapinar, P. B. (2010). The Relationship Between Self-Efficacy and Conflict-Handling Styles in Terms of Relative Authority Positions of the Two Parties. Social Behavior and Personality: An International Journal, 38(1), 13-28.

https://doi.org/10.2224/sbp.2010.38.1.13

Ford, C. M. (1996). A theory of individual creative action in multiple social domains. Academy of Management Review, 21(4), 1112-1142. https://doi.org/10.5465/AMR.1996.9704071865

Fuadiputra, I. R. (2020). EXPLORING TRANSFORMATIONAL LEADERSHIP, LEARNING ORIENTATION, AND CREATIVE SELF EFFICACY ON EMPLOYEE CREATIVITY. International Journal of Economics, Business and Accounting Research (IJEBAR), 4(4), 340-352.

Hair, J. F., Black, W. C., Babin, B. J., \& Anderson, R. E. (2010). Multivariate Data Analysis (7th Editio). New York: Prentice Hall International, Inc. 
Holman, D., Totterdell, P., Axtell, C., Stride, C., Port, R., Svensson, R., \& Zibarras, L. (2012). Job Design and the Employee Innovation Process: The Mediating Role of Learning Strategies. Journal of Business and Psychology, 27(2), 177-191. https://doi.org/10.1007/s10869-0119242-5

Hsu, M. L. A., Hou, S. T., \& Fan, H. L. (2011). Creative self-efficacy and innovative behavior in a service setting: Optimism as a moderator. Journal of Creative Behavior, 45(4), $258-272$. https://doi.org/10.1002/j.2162-6057.2011.tb01430.x

Ionica, O. (2013). The Impact of Innovation in Romanian Small and Medium-Sized Enterprises on Economic Growth Development. Journal of Knowledge Management, Economics and Information Technology, 3(6), 1-29.

Jha, S., \& Bhattacharyya, S. S. (2013). Learning Orientation and Performance Orientation: Scale Development and Its Relationship with Performance. Global Business Review, 14(1), $43-54$. https:/ / doi.org/10.1177/0972150912466443

Jiang, W., \& Gu, Q. (2017). Leader creativity expectations motivate employee creativity: a moderated mediation examination. International Journal of Human Resource Management, 28(5), 724-749. https://doi.org/10.1080/09585192.2015.1109535

Jiménez-Jimenez, D., Sanz, R. V., \& Hernandez-Espallardo, M. (2008). Fostering innovation: The role of market orientation and organizational learning. European Journal of Innovation Management, 11(3), 389-412. https://doi.org/10.1108/14601060810889026

Karadag, D. H. (2016). The Role of SMEs and Entrepreneurship on Economic Growth in Emerging Economies within the Post-Crisis Era: an Analysis from Turkey. Journal of Small Business and Entrepreneurship Development, 4(1). https://doi.org/10.15640/jsbed.v4n1a3

Kashif, M. T., Jamil, K., Khurshid, M. K., Amjad, M., \& Anjum, A. (2019). RELATIONSHIP BETWEEN LEARNING ORGANIZATION AND CREATIVITY IN TEACHING HOSPITALS. International Transaction Journal of Engineering, Management, \& Applied Sciences \& Technologies, 10(10), 1-6. https://doi.org/10.14456/ITJEMAST.2019.125

Kmieciak, R. (2020). Trust, knowledge sharing, and innovative work behavior: empirical evidence from Poland. European Journal of Innovation Management. https: / / doi.org/10.1108/EJIM-042020-0134

Kozlowski, S. W. J., Gully, S. M., Brown, K. G., Salas, E., Smith, E. M., \& Nason, E. R. (2001). Effects of training goals and goal orientation traits on multidimensional training outcomes and performance adaptability. Organizational Behavior and Human Decision Processes, 85(1), 131. https://doi.org/10.1006/obhd.2000.2930

Lee, C., Hallak, R., \& Sardeshmukh, S. R. (2019). Creativity and innovation in the restaurant sector: Supply-side processes and barriers to implementation. Tourism Management Perspectives, 31(July 2018), 54-62. https://doi.org/10.1016/j.tmp.2019.03.011

Lemon, M., \& Sahota, P. S. (2004). Organizational culture as a knowledge repository for increased 
innovative capacity. Technovation, 24(6), 483-498. https://doi.org/10.1016/S0166-4972(02)00102-5

Lu, L., Lin, X., \& Leung, K. (2012). Goal orientation and innovative performance: The mediating roles of knowledge sharing and perceived autonomy. Journal of Applied Social Psychology, 42(SUPPL. 1), 180-197. https://doi.org/10.1111/j.1559-1816.2012.01018.x

Miron-Spektor, E., \& Beenen, G. (2015). Motivating creativity: The effects of sequential and simultaneous learning and performance achievement goals on product novelty and usefulness. Organizational Behavior and Human Decision Processes, 127, 53-65. https://doi.org/10.1016/j.obhdp.2015.01.001

Mutonyi, B. R., Slåtten, T., \& Lien, G. (2020). Empowering leadership, work group cohesiveness, individual learning orientation and individual innovative behaviour in the public sector: empirical evidence from Norway. International Journal of Public Leadership, 16(2), 175-197. https://doi.org/10.1108/ijpl-07-2019-0045

Newman, A., Tse, H. H. M., Schwarz, G., \& Nielsen, I. (2018). The effects of employees' creative selfefficacy on innovative behavior: The role of entrepreneurial leadership. Journal of Business Research, 89(March), 1-9. https://doi.org/10.1016/j.jbusres.2018.04.001

Nguyen, T. P. L., Nguyen, K. N., Do, T. D., \& Nguyen, T. T. M. (2019). Knowledge sharing and innovative work behavior: The case of Vietnam. Uncertain Supply Chain Management, 7(4), 619-634. https://doi.org/10.5267/j.uscm.2019.5.001

Omri, W. (2015). Innovative behavior and venture performance of SMEs: The moderating effect of environmental dynamism. European Journal of Innovation Management, 18(2), 195-217. https://doi.org/10.1108/EJIM-02-2013-0015

Rhee, J., Park, T., \& Lee, D. H. (2010). Drivers of innovativeness and performance for innovative SMEs in South Korea: Mediation of learning orientation. Technovation, 30(1), 65-75. https://doi.org/10.1016/j.technovation.2009.04.008

Richter, A. W., Hirst, G., van Knippenberg, D., \& Baer, M. (2012). Creative self-efficacy and individual creativity in team contexts: Cross-level interactions with team informational resources. Journal of Applied Psychology, 97(6), 1282-1290. https://doi.org/10.1037/a0029359

Runhaar, P., Bednall, T., Sanders, K., \& Yang, H. (2016). Promoting VET teachers' innovative behaviour: exploring the roles of task interdependence, learning goal orientation and occupational self-efficacy. Journal of Vocational Education and Training, 68(4), 436-452. https://doi.org/10.1080/13636820.2016.1231215

Seo, H. M., Kim, M. C., Chang, K., \& Kim, T. (2016). INFLUENCE of INTERPERSONAL TRUST on INNOVATIVE BEHAVIOUR of SERVICE WORKERS: MEDIATING EFFECTS of KNOWLEDGE SHARING. International Journal of Innovation Management, 2O(2), 1-21. https://doi.org/10.1142/S1363919616500262 
Slater, S. F., \& Narver, J. C. (1995). Market Orientation and the Learning Organiza. Journal of Marketin, 59, 63-75. https://doi.org/10.1515/cks-2016-0005

Sousa, C. M. P., Coelho, F., \& Guillamon-Saorin, E. (2012). Personal Values, Autonomy, and Selfefficacy: Evidence from frontline service employees. International Journal of Selection and Assessment, 20(2), 159-170. https://doi.org/10.1111/j.1468-2389.2012.00589.x

Suliyanto, \& Rahab. (2012). The role of market orientation and learning orientation in improving innovativeness and performance of small and medium enterprises. Asian Social Science, 8(1), 134-145. https://doi.org/10.5539/ass.v8n1p134

Thurlings, M., Evers, A. T., \& Vermeulen, M. (2015). Toward a Model of Explaining Teachers' Innovative Behavior: A Literature Review. Review of Educational Research, 85(3), 430-471. https://doi.org/10.3102/0034654314557949

Tierney, P., \& Farmer, S. M. (2011). Creative Self-Efficacy Development and Creative Performance Over Time. Journal of Applied Psychology, 96(2), 277-293. https://doi.org/10.1037/a0020952

Tran, K., Nguyen, P., \& Nguyen, L. (2018). The Role of Financial Slack, Employee Creative SelfEfficacy and Learning Orientation in Innovation and Organizational Performance. Administrative Sciences, 8(4), 82. https://doi.org/10.3390/admsci8040082

Wang, C. L. (2016). What comes first: market or entrepreneurial orientation? Strategic Direction, 32(10), 7-9. https://doi.org/10.1108/sd-07-2016-0110

Yuan, F., \& Woodman, R. W. (2010). Innovative behavior in the workplace: The role of performance and image outcome expectations. Academy of Management Journal, 53(2), 323-342. https://doi.org/ 10.5465/amj.2010.49388995 